\title{
Mitchell, D. (2021). El lenguaje de la música moderna [Introducción de E. W. Said. Traducción de J. Lucas]. Barcelona: Acantilado, 238 pp. ISBN: 978-84-18370-27-4.
}

La colección de música de la editorial barcelonesa Acantilado constituye una de las series de mayor interés en los últimos tiempos. Se trata de monografías que engloban la reflexión y los estudios de especialistas de renombre, tanto nacionales e internacionales, algunos de tanto prestigio como es el caso de intérpretes como Alfred Brendel, Ian Bostridge, Nikolaus Harnonkourt, Wilhelm Furtwängler o John E. Gardiner, o de musicólogos como Heinrich Eggebrecht, Carl Dahlhaus, Mark Evan Bonds, Jan Swafford, Ramón Andrés o Jordi Pons, entre otros, sin renunciar a la publicación de obras emblemáticas del pasado histórico, como el Viaje musical por Francia e Italia en el s. XVIII, de Charles Burney, obra fundamental para conocer el ambiente musical en aquellos países durante la época de la Ilustración, narrada en primera persona. Dichas publicaciones han posibilitado que una parte esencial de la historiografía musical esté al alcance del lector en lengua castellana.

El último volumen de temática musical que ha publicado Acantilado se debe a Donald Mitchell y lleva el título de El lenguaje de la música moderna, otro libro clásico, datado en 1963, y que ya había sido publicado en español por la editorial Lumen en una edición (1972) que era ya imposible de encontrar. En esta ocasión, la editorial de Barcelona ha tenido el acierto indudable de reeditar esta obra en traducción impecable de Juan Lucas. Mitchell, nacido en 1925 en la capital británica, fundó tras la Segunda Guerra Mundial la prestigiosa revista Music Survey y por tal razón, ha cultivado tanto la investigación como la crítica musical en su propia revista y en otros medios de la prensa. Además, fue editor musical de la editorial Faber Music, en la que se responsabilizó de la edición de la obra tardía de Benjamin Britten, y es autor, entre otras obras, de una célebre trilogía sobre el compositor austriaco Gustav Mahler. Mitchell, fallecido en 2017, ejerció la docencia musical en las universidades de Sussex, York y King's College de Londres.

En su introducción, afirma Edward Said lo siguiente: "las palabras clave de Donald Mitchell son comunicación, comprensibilidad, discurso, dirección, entendimiento y demás. Sobre estos términos se apoya la rigurosa inteligencia crítica que opera en este libro, así como una actitud hacia la música ( $\mathrm{y}$ también hacia otras cosas implacablemente opuesta a la ofuscación, el hermetismo, el provincialismo, la jerga y demás". Para enhebrar su estudio, Mitchell se ha centrado en las personalidades musicales de dos autores que marcaron decisivamente y desde distintos puntos de partida, el rumbo de la música contemporánea durante el siglo XX: Arnold Schönberg e Igor Stravinski, a los que atribuye el autor el mérito de revelar "nuevos ámbitos de sentimiento" a través de su arte mediante una 
combinación fascinante de técnica, construcción formal y disciplina, como fiel manifestación de la sensibilidad de un tiempo, ansioso en la creación de nuevas expresiones artísticas. En un lenguaje profundo, pero al mismo tiempo accesible para el lector, hilvana Mitchell una serie de pensamientos e ideas de carácter interdisciplinar que dotan al libro de un interés cultural inusitado: así por ejemplo, al primer capítulo ("Schönberg: el principio susceptible de servir como norma") le sigue un segundo, titulado "Intersecciones con el cubismo", vinculando el nacimiento del nuevo método dodecafónico con la pintura de Picasso y estableciendo un sugerente paralelismo entre ambos autores y corrientes: "Como los compositores, el pintor tuvo que renunciar al lenguaje que con tanta maestría había utilizado en sus periodos Azul y Rosa para crear, a partir de su pintura y de su experiencia artística íntima, la forma nueva capaz de traducir su nuevo modo de percepción “ (pág. 89). Insiste Donald Mitchell que un aspecto común que relaciona a los mencionados compositores con el padre del cubismo es que todos ellos debieron renunciar a sus primeros estilos, por lo que, en su opinión, es factible hablar de una ruptura radical entre lo Viejo y lo Nuevo, y no de una evolución gradual.

Sobresale asimismo las ideas de Mitchell en torno al cambio brusco que adoptó la trayectoria de Stravinski, después de una etapa presidida por el lenguaje neoclásico, en al que fue totalmente reacio a la admisión de los procedimientos seriales: sin embargo, desde 1953, y una vez fallecido Schönberg, dichos procedimientos se convierten en el paradigma del quehacer estilístico del compositor ruso, momento en el que se unen los dos grandes representantes del modernismo musical. "Ni el historiador más perspicaz podría haber adivinado un desenlace más pulcro” (pág. 129), afirma el autor.

No es de menor interés las reflexiones sobre las relaciones de Schönberg con Kandinski ${ }^{1}$, cuya correspondencia supuso un hito de la modernidad del siglo XX, en un proceso que vuelve a demostrar la importancia del paralelismo entre el abandono de la figuración por parte del pintor ruso y la adopción de un nuevo método de composición que sustituía a la tradicional tonalidad por parte del compositor austriaco. Mitchell destaca en su libro, partiendo del análisis de los escritos de Schönberg, la elevada concepción de éste y su preocupación, compartida por Kandinski, por lo espiritual.

La traducción del libro de Mitchell, a cargo de Juan Lucas, director de la revista Scherzo, es magnífica: ya nos llamó la atención su extraordinaria labor literaria en la traducción del libro de Swafford sobre Beethoven (también aparecido en Acantilado), y el mejor elogio que se puede decir de Lucas es que el lector obtiene la sensación que tanto Swafford como Mitchell han escrito originalmente la obra en lengua española.

En resumidas cuentas, se trata de un libro útil para el mejor conocimiento de los estilos musicales actuales y, pese al tiempo trascurrido, sigue gozando de interés por haber sido escrito por uno de los especialistas más prestigiosos en el estudio de la música del siglo

\footnotetext{
1 Véase al respeto el libro Schönberg, A. \& Kandinsky, W. (1988). Arnold Schönberg. Wassily Kandinsky: cartas, cuadros y documentos de un encuentro extraordinario. Madrid: Alianza editorial.
} 
RESEÑAS DE LIBROS

XX y del nacimiento de los primeros modernismos musicales. Como siempre, esperaremos con expectación las próximas novedades musicales que nos depare la editorial Acantilado.

Paulino Capdepón Verdú

Universidad de Castilla-La Mancha Centro de Investigación y Documentación Musical (CIDoM)-Unidad Asociada al CSIC ORCID iD: https://orcid.org/0000-0001-6509-3496 